\title{
How do practically trained (student) caregivers in nursing homes learn? A scoping review
}

\author{
Irene J.M. Muller-Schoof*1, Marjolein E.A. Verbiest ${ }^{1}$, Annerieke Stoop ${ }^{1}$, Miranda Snoeren ${ }^{2}$, Katrien G. Luijkx ${ }^{1}$ \\ ${ }^{1}$ Tranzo, Scientific Center for Care and Wellbeing, Tilburg School of Social and Behavioral Sciences, Tilburg University, The \\ Netherlands \\ ${ }^{2}$ Fontys University of Applied Sciences, School of People and Health Studies, Eindhoven, The Netherlands
}

Received: August 9, 2021

Accepted: August 16, 2021

Online Published: August 30, 2021

DOI: $10.5430 /$ jnep.v12n1p25

URL: https://doi.org/10.5430/jnep.v12n1p25

\begin{abstract}
Background and objective: Practically trained (student) caregivers (further: caregivers) make up the majority of care staff in nursing homes (NHs). To keep up with the fast-changing healthcare environment and ensure a high quality of care, it is important to know how to stimulate continuous work-based learning (WBL) among this group. The purpose of the study was to systematically study the scientific literature published to date on (1) how caregivers learn in NHs and (2) what facilitates or impedes their learning.

Methods: A scoping review was carried out, systematically searching six scientific databases. A total of 35 studies published from January 2009 to February 2021 were included. Study characteristics, learning mechanisms, facilitators, and barriers to learning were extracted and synthesized.

Results: None of the studies specifically focused on how caregivers learn. Yet, we identified various learning mechanisms, and found that learning by theory or supervision was most frequently engaged in. Most learning mechanisms used among the groups in the included studies were planned and formal and developed and initiated by others out of the context. Three main themes were identified among the facilitators and barriers of WBL: individual learning, collective learning, and resources for learning. An interdependency between (sub)themes was found.

Conclusions: The way caregivers in NHs learn is understudied. Moreover, both their informal learning and the support they receive to be(come) active learners has been overlooked. As WBL provides caregivers with opportunities to learn within a real-life setting, we suggest more research on informal learning mechanisms.
\end{abstract}

Key Words: Learning, Work-based learning, Practically trained caregivers, Students, Nursing homes

\section{INTRODUCTION}

Nursing homes (NHs) offer care and support to people with serious health problems for whom living at home is no longer feasible because of the intensive help they need. ${ }^{[1]}$ The volume of residents in NHs and the complexity of health problems they present have increased rapidly in the past few years. ${ }^{[1]}$ Besides these challenges, NHs are transforming from a medicalized, routine-driven, and institutional setting to a more personalized, home-like setting ${ }^{[2]}$ in which innovative care and support methods and technology are increasingly being used. The standard for good quality care and applying new scientific knowledge is continuing to be developed in NH workplaces. This requires an agile, caring, and supportive staff, who are able to adapt to these new working

\footnotetext{
* Correspondence: Irene J.M. Muller-Schoof; Email: i.j.m.muller-schoof@tilburguniversity.edu; Address: Tranzo, Scientific Center for Care and Wellbeing, Tilburg School of Social and Behavioral Sciences, Tilburg University, The Netherlands.
} 
conditions. It also requires well-prepared care students. In this context, it is important to know how to prepare the caring staff and students in NHs for these developments.

As has long been recognized, students and caring staff predominately learn to take care of residents in NHs in and through work. ${ }^{[3-5]}$ As has been stated, "The everyday work in healthcare is the basis for learning". ${ }^{[6]}$ We refer to this learning as work-based learning (WBL). In general, WBL is facilitated by intentional guidance and sequenced access to workplace activities. ${ }^{[6,7]}$ Key contributors to WBL are: (a) engagement in everyday work tasks, (b) direct or close guidance of coworkers, and (c) indirect guidance provided by the workplace itself and others in the workplace. ${ }^{[7]}$ The interplay between "the degree by which individuals are invited to participate in and learn through work practices" (affordances) and "how individuals engage in activities and participate," are a typical dynamic of WBL. ${ }^{[7,8]}$ Another characteristic of WBL is that it involves both individual and collective learning. ${ }^{[9]}$ Furthermore, WBL is particularly informal, and involves cocreation and collaboration with others (e.g., colleagues, residents, and allied healthcarers), which is both planned and unplanned as a result of circumstances, such as the unpredictable behavior of residents. ${ }^{[10,11]}$ WBL can also be formal, intentional, and planned, as well as being related to work, but outside the workplace, with classroom teaching or workshops, for instance. ${ }^{[10,11]}$

Different professions can be distinguished within the caring staff in NHs, such as registered nurses (RNs), licensed practical nurses (LPNs), health care assistants (HCAs), certified nursing assistant (CNAs), and unregulated care workers. The profession of $\mathrm{RN}$ is recognized worldwide, and classified as an (applied) academic profession, at the tertiary level. ${ }^{[12,13]}$ No such worldwide standardization exists for the other care professionals within the NH's employ. In some countries, very limited or no formal education is required to be allowed to work as a care professional in a NH. Staff qualifications can range from no education to three-year secondary vocational education. We will refer to this group of care professionals - who are not RNs - including students, as practically trained caregivers, in short, caregivers.

Much research has been done to explore ways (student) RNs learn and acquire knowledge. ${ }^{[14-25]}$ However, less is known about the ways caregivers within NHs learn in work-based settings, even though in Western society the vast majority (about $80 \%$ ) of the care and support in NHs is provided by them. ${ }^{[25-28]}$ To the best of our knowledge, no reviews have previously synthesized the available research on ways this group of caregivers learn. Therefore, the aim of this scoping review is to examine and summarize: (1) how practically trained caregivers learn in the domain of NH care, and (2) what facilitates or impedes them in their learning and supports the quality of their learning and their development.

\section{METHODS}

In order to explore, map, and synthesize information on the WBL of practically trained caregivers in NHs, we performed a scoping review, following these five steps: (1) identifying research questions, (2) identifying relevant studies, (3) study selection, (4) charting the data, and (5) collating, summarizing, and reporting the results. ${ }^{[29,30]}$

\subsection{Identifying research questions}

Our research questions were as follows:

1) How do practically trained caregivers obtain WBL in the NH context?

2) What are the facilitators and barriers of WBL for practically trained caregivers in the NH context?

\subsection{Identifying relevant studies}

Papers of interest were expected to have been published in psychological, healthcare, educational, and nursing journals. A literature search was conducted in the following databases to search for scientific papers in English: Embase, Medline, Web of Science Core Collection, ERIC, CINAHL, and PsycINFO. We combined the search terms of three categories: (1) population (practically trained caregivers); (2) objective (WBL); and (3) care setting (nursing homes) in order to search in the titles and/or abstracts of potentially relevant papers (see Appendix A). The search was performed in November 2019 and updated in February 2021.

\subsection{Selecting relevant studies}

Articles were eligible if they met the following inclusion criteria:

\subsubsection{Type of participants}

We searched for studies focusing on, wholly or partially, practically trained caregivers. The healthcare staff population in NHs is a heterogenous group, with a wide variety of levels of education and titles. ${ }^{[31,32]}$ We focus on practically trained caregivers with no formal education to those with secondary vocational education. In practice, this varies from the (equivalent) education level of unregulated care workers to LPNs. As the nature of WBL is both individual and collective, for this scoping review we included articles with a mix of study participants, specifically RNs, allied healthcarers, and caregivers. Studies that solely focused on nurses with a degree in higher or tertiary education were excluded. 


\subsubsection{Objective}

We sought studies that focused on how caregivers obtain WBL and/or studies that focused on the facilitators of, and barriers to, WBL for this group. Facilitators and barriers are defined as anything that made WBL easier or more difficult for caregivers.

\subsubsection{Context}

We were interested in studies where $\mathrm{NH}$ care for older adults was the setting.

\subsubsection{Type of source}

Original, peer-reviewed empirical research, studies written in English, and actual studies published from the year 2009 were included. In the rapidly changing research landscape, we decided to include studies that were no more than ten years old, at the time of our initial search in 2019. Papers not written in English or not retrievable, and non-scientific papers (e.g., editorials) were excluded.

\subsection{Charting the data}

In the first screening phase, duplicates were removed, and unique titles were screened by one reviewer (author 1). In the second screening phase, abstracts and full text articles were assessed by two reviewers (author 1 and 2 or 3 ) independently. A self-developed extraction form was used to capture all relevant aspects. This form included information on the study aim, country, study design, methodology, intervention characteristics (if applicable), data collection and analysis procedures, outcome measures, and the key findings of the publications including the WBL of caregivers, the learning results, and facilitators of, and barriers to, WBL. Author 1 assessed all 35 publications; author 2 and 3 assessed 21 and 14 articles, respectively. Forms were compared and disagreements were discussed until consensus was reached.

\subsection{Collating, summarizing, and reporting the results}

We examined and summarized the basic characteristics of the studies included. We also systematically analyzed the results of the included studies to answer the main research question on how practically trained caregivers learn within NHs. We identified learning mechanisms within each study, based on the hospital nursing framework of Berings et al., ${ }^{[15]}$ as this framework on learning mechanisms was the most suitable for the NH context. The framework identifies eight learning mechanisms, including learning by: 1) doing one's regular job, 2) applying something new in the job, 3) social interaction with colleagues, 4) theory or supervision, 5) reflection, 6) making intermediate adjustments, 7) looking back, and 8) through life outside work. ${ }^{[15]}$ Two reviewers (author 1 and 2) independently identified the learning mechanisms in seven randomly selected studies. After comparing the findings and reaching consensus on the assignment process, one reviewer Published by Sciedu Press identified the learning mechanism of the remaining studies (author 1).

Based on thematic analysis of the facilitators and barriers of WBL as identified in the studies included, themes and subthemes were developed, after which they were translated into a model. ${ }^{[33]}$ To build the model, we found inspiration from the WBL framework of Manley et al. (6). To the best of our knowledge, there is no existing WBL model for caregivers in the $\mathrm{NH}$ context.

\section{Results}

Figure 1 shows the screening process. The initial search in November 2019 resulted in 28 included studies. The search was updated in February 2021, which resulted in seven additional included studies, bringing the total number to 35 .

\subsection{Study characteristics}

Characteristics of the 35 included studies are presented in Appendix B. The studies included were published between 2009 and 2021 and came from 11 different countries; the majority were conducted in Europe $(n=20)$, followed by North America $(n=9)$, Oceania $(n=5)$, and Asia $(n=1)$.

Although our review focused solely on practically trained caregivers, the participants of most of the studies included consisted of mixed occupations. In most studies, caregivers comprised more than $50 \%$ of the study population $(n=26)$, and in five studies, the population studied consisted of $100 \%$ caregivers. ${ }^{[34-38]}$

In total, 24 studies evaluated an educational intervention (see Appendix B). In 22 out of 24 intervention studies, persons other than the learners themselves decided about the education provided. Most of these interventions were initiated by researchers $(n=16)$, followed by managers $(n=8)$, and ministries of healthcare $(n=2)$. Only two of the intervention studies were initiated as a result of the direct learning needs of the caregivers. ${ }^{[38,39]}$ In three studies, the intervention took place in a workplace context, ${ }^{[38,40,41]}$ in six studies the intervention was outside the workplace, with a followup in the workplace context, ${ }^{[42-47]}$ and the majority of the interventions took place completely outside the workplace.

\subsection{Learning mechanisms}

Appendix $\mathrm{C}$ gives an overview of the learning mechanisms we identified in 28 of the 35 studies included. Overall, we found that "learning by theory or supervision" was most often studied $(\mathrm{n}=26)$, followed by "learning by social interaction with colleagues" $(\mathrm{n}=13)$, and "learning by looking back" $(n=12)$. Finally, we found "action research" as a learning mechanism in two studies, ${ }^{[46,48]}$ which we could not fit into the model of Berings et al. 

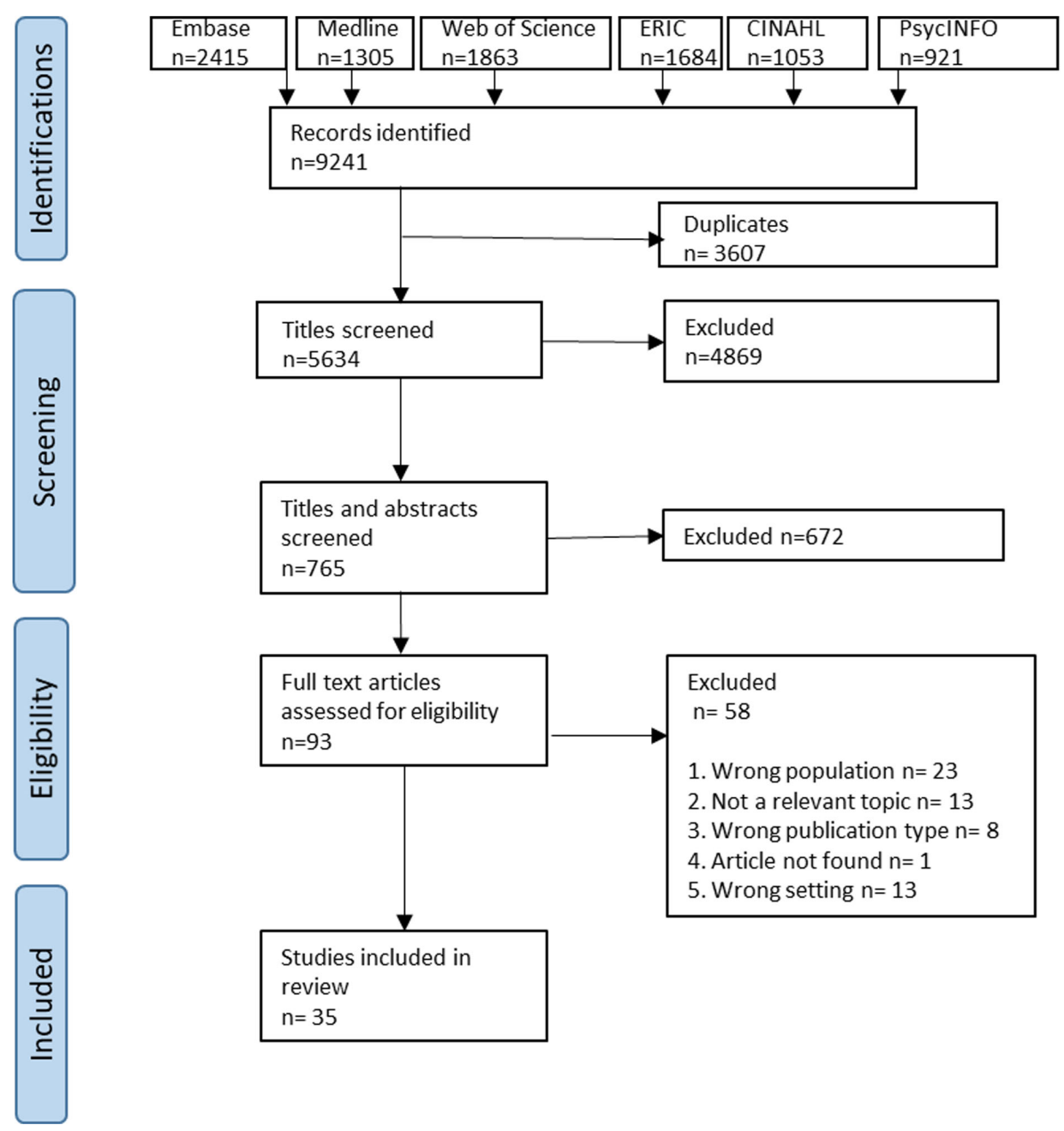

Studies included in review

$\mathrm{n}=35$

Figure 1. Flow chart of selection process

\subsection{Facilitators and barriers of learning}

Overall, we identified a total of 81 facilitators and 75 barriers of WBL among caregivers in nursing homes (see Appendix B). We summarized these into three main themes and several subthemes and translated this into a model to provide insight into the dynamics, interaction, and interdependence between facilitators and barriers (see Figure 2). The three main themes facilitators and barriers are related to: 1) individual learning, 2) collective learning, and 3 ) resources for learning. Working with residents, including facing challenges such as complex care situations, is the basis of WBL in NHs. We found that working with residents both facilitated as well as impeded WBL among caregivers.

\subsubsection{Individual learning}

At an individual level, we found that motivation and an attitude of openness to feedback are facilitators for WBL, as an individual shows engagement in everyday work tasks and a willingness to learn from support and guidance. ${ }^{[34,42,45,48-52]}$ How an individual engages in work depends on the percep- tion of the teams' psychological safety and a perception of the consequences of interpersonal risk-taking, which can facilitate or impede WBL. ${ }^{[53,54]}$ We also found that caregivers' emotions influence WBL. For example, insecurity, stress, and fear, in combination with a lack of competences, are often a result of/associated with challenging work situations, such as a distressed resident and not knowing what to do. ${ }^{[38,42,45,55]}$ Residents' complex behaviors made learning among caregivers challenging, as some forgot what they had learned and others were not comfortable speaking about or sharing their thoughts. ${ }^{[43,44,52]}$ The same challenging situations can also trigger learning, when caregivers are, for example, eager to learn in order to relieve a resident's distress, share experiences, and reflect alone or together. ${ }^{[35,43,46,51]}$ Other emotions that influence WBL are courage and confidence, in combination with sharing and social support. ${ }^{[38,42,45,48,55]}$ Making time for social support, by debriefing after impactful moments (such as being with a dying resident) was important to be able to cope with emotions and to learn from such moments. ${ }^{[35,41,43-45]}$ 


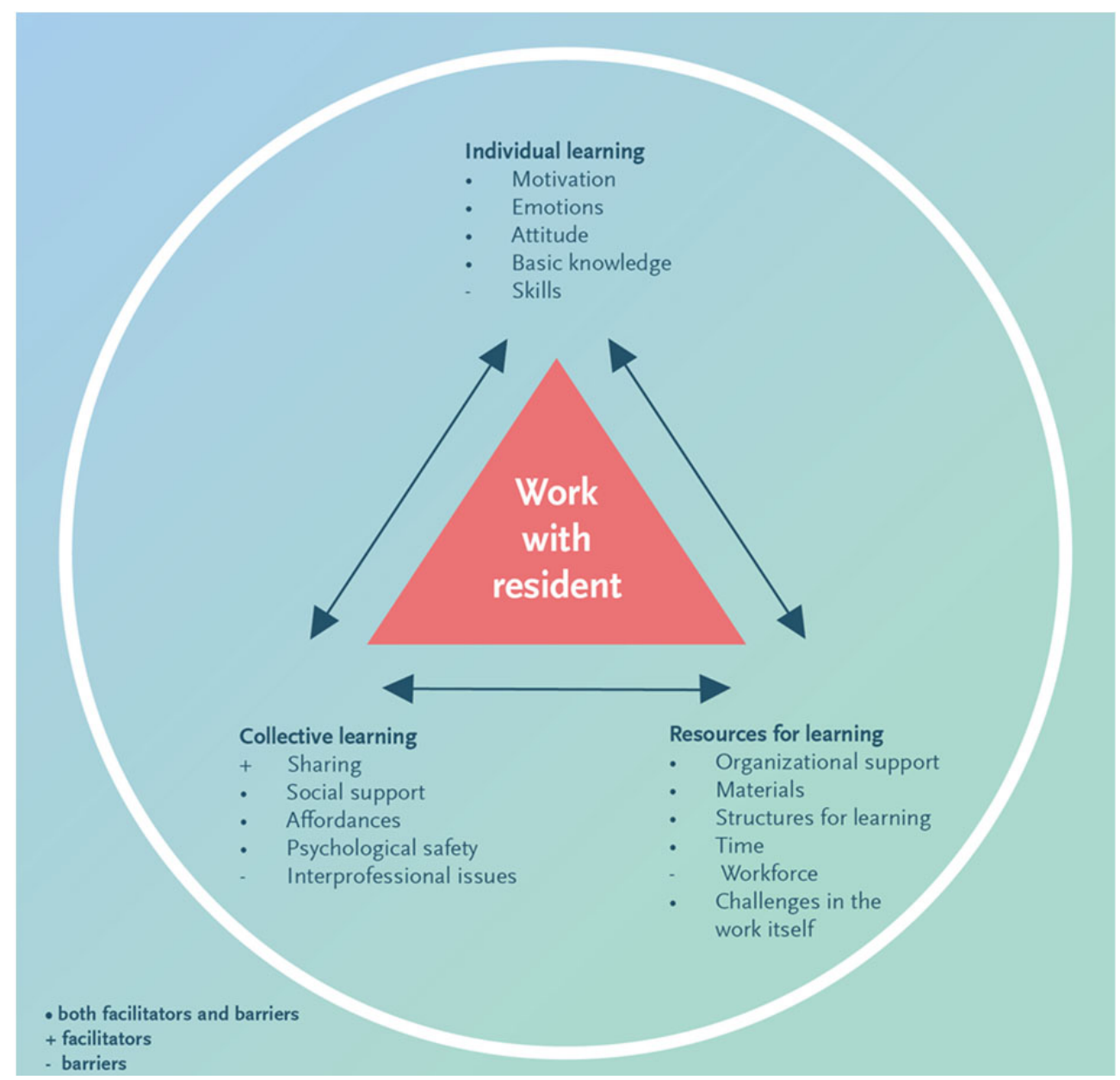

Figure 2. Model of facilitators and barriers of WBL caregivers in NHs

\subsubsection{Collective learning}

At a collective level, the articles show that learning is facilitated by an attractive workplace, with a safe team climate, and a good team spirit. In psychologically safe teams, caregivers are invited and reinforced to use new skills (affordance), the staff communicates well, shares knowledge, and takes time to reflect on experiences. ${ }^{[38,45,48-50,53,55-59]}$ In addition, psychological safety and affordances are facilitators of WBL when staff and students participate together in care situations, such as interprofessional consultation, changing projects, and action research. ${ }^{[46,48,56,60]}$ Conversely, we found that affordances can also be a barrier to individual learning, for instance, when novices are excluded from shift handovers, which are "acknowledged as important opportunities to discuss professional matters in a protected space". [50] In addition, another way of learning collectively with social support in a psychologically safe team, is learning from errors, by sharing knowledge, and reflecting on the process of how errors occurred. ${ }^{[3,53,54]}$ Psychological safety can be perceived as a barrier to WBL when teams are unstable, due, for instance, to a continually changing team composition, or Published by Sciedu Press when group reflections about care situations are unusual and social support is missing. ${ }^{[54,57]}$

\subsubsection{Resources for learning}

Resources represent, among other things, the learning infrastructure of an organization. This includes the organizational support and learning structures that enable WBL. Organizational support may consist of managers that are involved with individual and collective learning, or coaches offering support on the job. ${ }^{[46,48,54,56]}$ Not offering the opportunity to assimilate new skills in practice, ${ }^{[45,48,50,59]}$ and managers who lack a vision of WBL and therefore the motivation to maintain continuous $\mathrm{WBL}^{[37,58,59]}$ are reported barriers. We also found that learning structures offered to caregivers, such as systematic reflection on impactful work situations, or scheduled time for action research, facilitate WBL. ${ }^{[48,51,55,56]}$ Frequently mentioned barriers to learning were lack of time, lack of personnel, and high workload. Tight staff coverage is a barrier to allowing caregivers the opportunity to attend formal education without being stressed about the consequences of leaving their ward. ${ }^{[45,51,61]}$ It also results 
in caregivers having no energy left for learning because of workload $^{[51,62]}$ and burnouts. ${ }^{[44,62]}$ The content of learning materials should match existing knowledge and experience of the caregivers, ${ }^{[56,58,60]}$ instead of being too long, containing difficult vocabulary, or being incomprehensible. ${ }^{[36,63]}$

\section{Discussion}

This scoping review revealed that no previous studies focused exclusively on how practically trained caregivers obtain WBL in the NH context. Yet, we identified various learning mechanisms and found that learning by theory or supervision was most frequently studied. Most of the studies included investigated formal learning outside the workplace, such as workshops. Existing literature shows that WBL is predominantly informal and takes place inside the workplace. ${ }^{[4,6,10,11]}$ An explanation of why informal learning is not studied so frequently could be that it is not recognized as learning. If it is recognized as learning, then more attention should be devoted to informal WBL for caregivers in NHs. We suggest investigating how to organize more informal WBL for caregivers in the workplace. Moreover, if formal learning is offered, literature shows that education is more effective when reinforcing strategies - such as peer support - are provided to facilitate the transfer of knowledge to the workplace. ${ }^{[64-67]}$ The majority of the studies about formal learning lacked reinforcing strategies. We suggest supporting caregivers with a practical reinforcing strategy after formal learning, so that formal learning is more intertwined with the workplace.

Furthermore, literature on WBL shows that learners should be active learners, who are motivated, proactive, and who show initiative. ${ }^{[6,8,11]}$ However, this review shows that others than caregivers themselves, people such as researchers or managers predominantly initiated what and how caregivers learn. This may be inconsistent with the learners' motivation to learn and might deprive them of ownership of their own learning. We advise the involvement of caregivers in how their own WBL takes place, on what subjects they learn, and supporting them to be active and motivated learners.

Additionally, existing literature on WBL only reports the challenges of work itself as a facilitator. ${ }^{[4,6,8,11,68,69]}$ We found that work itself can also be a barrier to WBL among caregivers in NHs, especially when situations with residents are so challenging that it impedes caregivers in their learning. Therefore, we recommend that more attention should be paid to how caregivers can be supported to learn from challenging work situations, such as the offer of guidance by an experienced colleague, role model, or coach. ${ }^{[7,70,71]}$ The predicted increase of $\mathrm{NH}$ residents with complex problems underpins the importance of effective WBL, because it an- ticipates more complex work and unplanned interruptions in daily routines. ${ }^{[1]}$

Finally, we developed a model depicting (sub)themes of facilitators and barriers of learning among caregivers in NHs. Although the findings largely correspond with existing WBL models, ${ }^{[6,11]}$ our model shows the interrelatedness of all (sub)themes more explicitly. In this review, however, we were unable to unravel the relative importance of specific facilitators and barriers to learning among caregivers. More and in-depth insight into which facilitators and/or barriers are most important, and how these interrelate, will enable us to better support WBL for caregivers.

\subsection{Strengths and limitations}

Whereas previous studies primarily focused on learning among RNs, ${ }^{[14-24]}$ this scoping review is the first to focus on learning among practically trained caregivers, who make up the majority of the care staff in NHs worldwide. In addition, we developed a model that provides insight into the dynamics of facilitators and barriers of WBL among caregivers in NHs.

However, some limitations have to be taken into account when interpreting the findings. First, as the nature of WBL involves interaction with others, we decided to include all studies with caregivers, to capture as many relevant studies as possible. As a result, we found a large heterogeneity of participants in the studies included, however, in some studies, caregivers were only a small part. As such, no firm conclusions can be drawn on the way this specific target group learns. Furthermore, we did not consider the concomitant learning of students in their learning programs and their life stage, where they are more receptive to learning. Lastly, we have listed and ranked the facilitators and barriers on different levels, but no conclusions can be drawn on the relative importance of (sub)themes.

\subsubsection{Recommendations for future research}

We recommend further research on the question of how specifically practically trained caregivers obtain WBL in the NH context. Additionally, we argue that future research should focus on how caregivers learn informally, while working in challenging situations, and investigate the most effective ways to support them in these situations. Moreover, we advise the investigation of how to involve caregivers more in their own WBL. Furthermore, we suggest follow-up research on the facilitators and barriers that influence WBL, their interrelatedness, reciprocity, and relative importance in the WBL-model. 


\section{Conclusions}

The way practically trained caregivers learn in the NH context is understudied, and their informal learning has largely been overlooked. Moreover, caregivers' involvement in their own WBL deserves more attention. As WBL provides caregivers with opportunities to learn within a real-life setting, which includes the increasing challenges of a $\mathrm{NH}$ context, we suggest more informal learning and more research on informal learning mechanisms.

\section{FUNDING}

This work was funded by the Netherlands Organisation for Health Research and Development (ZonMw) [grant number
516022521, 2019]. The funder played no role in the design of the study, collection, analysis, or interpretation of data, or in writing the manuscript.

\section{ACKNOWLEDGeMENTS}

The authors wish to thank Dr. Wichor Bramer and his colleagues from the Erasmus MC Medical Library for developing the search strategies and conducting an update.

\section{CONFLiCTS OF INTEREST Disclosure}

No conflicts of interest have been declared.

\section{REFERENCES}

[1] Ocde O, Organisation for Economic C-o, Development. Integrating Social Services for Vulnerable Groups - Bridging Sectors for Better Service Delivery: OECD Publishing; 2015. Available from: http://www.myilibrary. com?id=820051 https://do i.org/10.1787/9789264233775-en

[2] Koren MJ. Person-centered care for nursing home residents: the culture-change movement. Health affairs (Project Hope). 2010; 29(2): 312-7. PMid:20056692 https://doi.org/10.1377/hlth aff. 2009.0966

[3] Billett S, Cooke M, Irby DM, et al. Educating Physicians: A Call for Reform of Medical School and Residency. The Carnegie Foundation for the Advancement of Teaching. Vocations and Learning. 2011; 4(1): 89-92. https ://doi .org/10.1007/s12186-010-9051-4

[4] Billett S. Learning through health care work: premises, contributions and practices. Medical Education. 2016; 50(1): 124-31. PMid:26695472 https://doi.org/10.1111/medu. 12848

[5] Cooke M, Irby DM, O'Brien BC. Educating Physicians : a Call for Reform of Medical School and Residency. Hoboken: John Wiley \& Sons; 2010. Available from: http://www.myilibrary.com?id= 268468

[6] Manley K, Titchen A, Hardy S. Work-based learning in the context of contemporary health care education and practice: A concept analysis. Practice Development in Health Care. 2009; 8(2): 87-127. https://doi.org/10.1002/pdh.284

[7] Billett S. Toward a Workplace Pedagogy: Guidance, Participation, and Engagement. Adult Education Quarterly. 2002; 53(1): 27-43. https://doi.org/10.1177/074171302237202

[8] Billett S. Co-Participation: Affordance and engagement at work. New Directions for Adult and Continuing Education. 2001; 2001(92): 63-72. https://doi.org/10.1002/ace. 41

[9] Fenwick T. Understanding Relations of Individual 2014;Collective Learning in Work: A Review of Research. Management Learning. 2008; 39(3): 227-43. https://doi.org/10.1177/1350507608 090875

[10] Eraut M. Informal learning in the workplace. Studies in Continuing Education. 2004; 26(2): 247-73. https://doi .org/10.1080/15 8037042000225245

[11] Tynjälä P. Perspectives into learning at the workplace. Educational Research Review. 2008; 3(2): 130-54. https://doi.org/10.101 $6 / j$.edurev.2007.12.001

Published by Sciedu Press
[12] Mistiaen P, Mistiaen P, Kroezen M, et al. Verpleegkundigen en verzorgenden in internationaal perspectief: een literatuurstudie naar rollen en posities van beroepsbeoefenaren in de verpleging en verzorging. NIVEL; 2011.

[13] Rafferty AM, Busse R, Zander-Jentsch B, et al. Strengthening health systems through nursing : evidence from 14 European countries. Copenhagen, Denmark: European Observatory on Health Systems and Policies; 2019. Available from: https://www.ncbi.nlm.nih .gov/books/NBK545724/

[14] Benner P. From Novice to Expert. The American Journal of Nursing 1982; 82(3): 402-7. https://doi.org/10.1097/00000446-198 282030-00004

[15] Berings M, Poell R, Gelissen J. On-the-job learning in the nursing profession: Developing and validating a classification of learning activities and learning themes. Personnel Review. 2008; 37(4): 442-59. https://doi.org/10.1108/00483480810877606

[16] Gopee N. Lifelong Learning in Nursing: Perceptions and Realities. Nurse Education Today. 2001; 21(8): 607-15. PMid:11884173 https://doi.org/10.1054/nedt.2001.0670

[17] Lawton S, Wimpenny P. Continuing professional development: a review. Nursing standard (Royal College of Nursing (Great Britain): 1987). 2003; 17(24): 41-4. PMid:12655859 https ://doi .org/10 $.7748 / \mathrm{ns} .17 .24 .41 . \mathrm{s} 52$

[18] Bleijenberg N. Dutch nursing students' knowledge and attitudes towards older people - A longitudinal cohort study. Journal of Nursing Education and Practice. 2012; 2(2). https ://doi.org/10.5430/ jnep.v2n2p1

[19] McCrow J, Yevchak A, Lewis P. A prospective cohort study examining the preferred learning styles of acute care registered nurses. Nurse Education in Practice. 2014; 14(2): 170-5. PMid:24075793 https://doi.org/10.1016/j.nepr.2013.08.019

[20] Cant R, Levett-Jones T. Umbrella review: Impact of registered nurses' continuing professional education informed by contemporary reviews of literature. Nurse Education in Practice. 2021; 50. PMid:33321270 https://doi.org/10.1016/j.nepr.2020.102945

[21] Fiset VJ, Graham ID, Davies BL. Evidence-Based Practice in Clinical Nursing Education: A Scoping Review. Journal of Nursing Education. 2017; 56(9): 534-41. PMid:28876439 https ://doi .org/10 .3928/01484834-20170817-04

[22] Jeppesen KHl, Christiansen S, Frederiksen K. Education of student nurses - A systematic literature review. Nurse Education Today. 2017; 
55: 112-21. PMid:28575708 https://doi.org/10.1016/j.ne dt.2017.05.005

[23] Stoffels M, Peerdeman SM, Daelmans HEM, et al. How do undergraduate nursing students learn in the hospital setting? A scoping review of conceptualisations, operationalisations and learning activities. BMJ Open. 2019; 9(12). PMid:31818833 https://doi .org/ 10.1136/bmjopen-2019-029397

[24] Backhaus R, Verbeek H, van Rossum E, et al. Future distinguishing competencies of baccalaureate-educated registered nurses in nursing homes. Geriatric nursing (New York, NY). 2015; 36(6): 438-44. PMid:26283584 https://doi.org/10.1016/j.gerinurse. 20 15.06 .012

[25] Andersson As, Frank C, Willman AML, et al. Factors contributing to serious adverse events in nursing homes. Journal of Clinical Nursing. 2018; 27(1-2): e354-e62. PMid:28618102 https: //doi.org/10.1111/jocn.13914

[26] Baughman RA, Smith KE. Labor mobility of the direct care workforce: Implications for the provision of long-term care. Health Economics. 2012; 21(12): 1402-15. PMid:22025403 https ://doi.or $\mathrm{g} / 10.1002 / \mathrm{hec} .1798$

[27] Organisation for Economic C-o, Development. A good life in old age? : monitoring and improving quality in longterm care. Paris: OECD/European Commission; 2013. Available from: https://public.ebookcentral.proquest.com /choice/publicfullrecord. aspx?p=1336579 https://doi org/10.1787/9789264194564-en

[28] Royal Commission into Aged Care Q, Safety. Research Paper 01 - How Australian Residential Aged Care Staffing Levels Compare with International and National Benchmarks. Adeliade, South Australia: Royal Commission into Aged Care Quality and Safety; 2019. Available from: https://nla.gov .au/nla.obj-2924408487

[29] Grant MJ, Booth A. A typology of reviews: an analysis of 14 review types and associated methodologies. Health information and libraries journal. 2009; 26(2): 91-108. PMid:19490148 https: //doi.org/10.1111/j.1471-1842.2009.00848.x

[30] Arksey H, O'Malley L. Scoping studies: towards a methodological framework. International Journal of Social Research Methodology. 2005; 8(1): 19-32. https://doi.org/10.1080/136455703200 0119616

[31] Hewko SJ, Cooper SL, Huynh H, et al. Invisible no more: a scoping review of the health care aide workforce literature. BMC Nursing 2015; 14(1). PMid:26203297 https://doi .org/10.1186/s129 $12-015-0090-\mathrm{x}$

[32] Moran A, Enderby P, Nancarrow S. Defining and identifying common elements of and contextual influences on the roles of support workers in health and social care: a thematic analysis of the literature. Journal of Evaluation in Clinical Practice. 2011; 17(6): 1191-9. PMid:20807287 https://doi.org/10.1111/j.1365-2753.20 10.01505.x

[33] Verboom B. Barriers and Facilitators Systematic Reviews in Health: A Methodological Review and Recommendations for Reviewers. Research Synthesis Methods. 2020; 11(6): 743-59. PMid:32845574 https://doi.org/10.1002/jrsm. 1447

[34] Haggstrom E, Bruhn S. Caregivers' attitudes to education and supervision in work with the older people in a nursing home. Nurse Education Today. 2009; 29(8): 850-4. PMid:19500887 https: //doi.org/10.1016/j.nedt.2009.05.002

[35] Leicher V, Mulder RH, Bauer J. Learning from Errors at Work: A Replication Study in Elder Care Nursing. Vocations and Learning: Studies in Vocational and Professional Education. 2013; 6(2): 207-20. https://doi.org/10.1007/s12186-012-9090-0
[36] Molinari V, Hobday JV, Roker R, et al. Impact of serious mental illness online training for certified nursing assistants in long term care. Gerontology \& Geriatrics Education. 2017; 38(4): 359-74. PMid:28632071

[37] Zulch D, Saunders R, Peters J, et al. Effectiveness of a service learning model with Allied Health Assistant students in aged care. International Journal of Training Research. 2016; 14(2): 161-70. https://doi.org/10.1080/14480220.2016.1203577

[38] Tornøe K, Danbolt LJ, Kvigne K, et al. A mobile hospice nurse teaching team's experience: training care workers in spiritual and existential care for the dying - a qualitative study. BMC Palliative Care. 2015; 14(1): 43. PMid:26385472 https://doi.org/10.1 186/s12904-015-0042-y

[39] Goodenough B, Watts J, Bartlett S. Making sense of self-reported practice impacts after online dementia education: The example of Bedtime to Breakfast and beyond. Brain Impairment. 2020; 21(3): 299-313. https://doi.org/10.1017/BrImp.2020.19

[40] Pitts K, Pudney K, Zachos K, et al. Using mobile devices and apps to support reflective learning about older people with dementia. Behaviour \& Information Technology. 2015; 34(6): 613-31. https://doi.org/10.1080/0144929X.2015.1015165

[41] Alamgir H, Drebit S, Li HG, et al. Peer coaching and mentoring : A new model of educational intervention for safe patient handling in health care. American Journal of Industrial Medicine. 2011; 54(8): 609-18. PMid:21630297 https://doi.org/10.1002/ajim. 209 68

[42] Dahl H, Jan D, Tone Elin M, et al. Facilitation of a workplace learning intervention in a fluctuating context: an ethnographic, participatory research project in a nursing home in Norway. International Practice Development Journal [Internet]. 2018; 8(2): 1-17. https://doi.org/10.19043/ipdj.82.004

[43] Douglas NF, MacPherson MK. Positive Changes in Certified Nursing Assistants' Communication Behaviors With People With Dementia: Feasibility of a Coaching Strategy. Am J Speech Lang Pathol. 2021; 30(1): 239-52. PMid:33472008 https://doi .org/10.1044/20 20_AJSLP-20-00065

[44] Fiset V, Luciani T, Hurtubise A, et al. Clinical Nursing Leadership Education in Long-Term Care: Intervention Design and Evaluation. Journal of Gerontological Nursing. 2017; 43(4): 49-56. PMid:28095585 https://doi.org/10.3928/00989134-20170 111-01

[45] Soderlund M, Norberg A, Hansebo Gr. Validation method training: nurses' experiences and ratings of work climate. International Journal of Older People Nursing. 2014; 9(1): 79-89. PMid:23601158 https://doi.org/10.1111/opn. 12027

[46] Torma J, Pingel R, Cederholm T, et al. Is it possible to influence ability, willingness and understanding among nursing home care staff to implement nutritional guidelines? A comparison of a facilitated and an educational strategy. Int J Older People Nurs. 2021: e12367.

[47] Westergren A. Action-Oriented Study Circles Facilitate Efforts in Nursing Homes to "Go from Feeding to Serving": Conceptual Perspectives on Knowledge Translation and Workplace Learning. Journal of Aging Research. 2012; 2012: 627371. PMid:22991666 https://doi.org/10.1155/2012/627371

[48] Snoeren M, Volbeda P, Niessen TJH, et al. Dutch care innovation units in elderly care: A qualitative study into students' perspectives and workplace conditions for learning. Nurse Education in Practice. 2016; 17: 174-81. PMid:26694313 https://doi.org/10.1016/ j.nepr.2015.11.005

[49] Fringer A, Huth M, Hantikainen V. Nurses' experiences with the implementation of the Kinaesthetics movement competence training into elderly nursing care: a qualitative focus group study. 
Scandinavian Journal of Caring Sciences. 2014; 28(4): 757-66. PMid:24387733 https ://doi .org/10.1111/scs . 12108

[50] Goller M, Steffen B, Harteis C. Becoming a Nurse Aide: An Investigation of an Existing Workplace Curriculum in a Nursing Home. Vocations and Learning: Studies in Vocational and Professional Education. 2019; 12(1): 67-85. https://doi.org/10.1007/s1 2186-018-9209-z

[51] van der Dam S, Schols JM, Kardol TJ, et al. The discovery of deliberation. From ambiguity to appreciation through the learning process of doing Moral Case Deliberation in Dutch elderly care. Social Science \& Medicine (1982). 2013; 83: 125-32. PMid:23410684 https://doi.org/10.1016/j.socscimed.2013.01.024

[52] Gillham D, De Bellis A, Xiao L, et al. Using research evidence to inform staff learning needs in cross-cultural communication in aged care homes. Nurse Education Today. 2018; 63: 18-23. PMid:29407255 https://doi.org/10.1016/j.nedt. 2018.01 .007

[53] Leicher V, Mulder RH. Team learning, team performance and safe team climate in elder care nursing. Team Performance Management. 2016; 22(7-8): 399-414. https://doi.org/10.1108/TPM-04-2 016-0017

[54] Buljac-Samardzic M, van Woerkom M, Paauwe J. Team safety and innovation by learning from errors in long-term care settings. Health care management review. 2012; 37(3): 280-91. PMid:22008722 https://doi.org/10.1097/HMR.0b013e318231db33

[55] Lichtwarck B, Myhre J, Goyal AR, et al. Experiences of nursing home staff using the targeted interdisciplinary model for evaluation and treatment of neuropsychiatric symptoms (TIME) - a qualitative study. Aging \& Mental Health. 2019; 23(8): 966-75. PMid:29669442 https://doi.org/10.1080/13607863.2018.1464116

[56] Anvik C, Vedeler JS, Wegener C, et al. Practice-based learning and innovation in nursing homes. Journal of Workplace Learning. 2020; 32(2): 122-34. https://doi.org/10.1108/JWL-09-2019-011 2

[57] Augustsson H, Tornquist A, Hasson H. Challenges in transferring individual learning to organizational learning in the residential care of older people. Journal of Health Organization and Management. 2013; 27(3): 390-408. PMid:23885400 https://doi.org/10.1 108/JHOM-Sep-2012-0163

[58] Farrington CJ. Blended e-learning and end of life care in nursing homes: a small-scale mixed-methods case study. BMC Palliative Care. 2014; 13: 31. PMid:24994948 https ://doi .org/10.1186/ 1472-684X-13-31

[59] Gallagher A, Peacock M, Zasada M, et al. Care-givers' reflections on an ethics education immersive simulation care experience: A series of epiphanous events. Nursing inquiry. 2017; 24(3). PMid:28004462 https://doi.org/10.1111/nin.12174
[60] Halabisky B, Humbert J, Stodel EJ, et al. eLearning, knowledge brokering, and nursing: strengthening collaborative practice in long-term care. Computers, informatics, nursing: CIN. 2010; 28(5): 264-73. PMid:20736723 https://doi.org/10.1097/NCN.0b013e3181 ec28b9

[61] Gleason LJ, Martinchek M, Long M, et al. An innovative model using telementoring to provide geriatrics education for nurses and social workers at skilled nursing facilities. Geriatric nursing (New York, NY). 2019; 40(5): 517-21. PMid:30987777 https : //doi .org/10 $.1016 / j$.gerinurse .2019 .03 .018

[62] Frey R, Robinson J, Gott M, et al. Burnout matters: The impact on residential aged care staffs' willingness to undertake formal palliative care training. Progress in Palliative Care. 2015; 23(2): 68-74. https://doi.org/10.1179/1743291X14Y.0000000096

[63] Habes EV, Jepma P, Parlevliet JL, et al. Video-based tools to enhance nurses' geriatric knowledge: A development and pilot study Nurse Educ Today. 2020; 90: 104425. PMid:32311666 https: //doi.org/10.1016/j.nedt.2020.104425

[64] Burgio LD, Burgio KL. Institutional Staff Training and Management: A Review of the Literature and a Model for Geriatric, Long-Term-Care Facilities. International Journal of Aging and Human Development. 1990; 30(4): 287-302. PMid:2118881 https: //doi.org/10.2190/B1PX-OA1D-NB49-KDFA

[65] Broad ML. Overview of Transfer of Training: From Learning to Performance. Performance Improvement Quarterly. 2008; 10(2): 7-21. https://doi.org/10.1111/j.1937-8327.1997.tb00046.x

[66] Stolee P, Esbaugh J, Aylward S, et al. Factors associated with the effectiveness of continuing education in long-term care. The Gerontologist. 2005; 45(3): 399-409. PMid:15933280 https ://doi.or g/10.1093/geront/45.3.399

[67] Aylward S, Stolee P, Keat N, et al. Effectiveness of continuing education in long-term care: a literature review. The Gerontologist. 2003; 43(2): 259-71. PMid:12677083 https://doi .org/10.1093/ge ront/43.2.259

[68] Billett S. Learning through Work: Workplace Affordances and Individual Engagement. Journal of Workplace Learning. 2001; 13(5): 209-14. https://doi.org/10.1108/EUM0000000005548

[69] Eraut M. Learning contexts. Learning in Health and Social Care. 2006; 5(1): 1-8. https://doi.org/10.1111/j.1473-6861.20 $06.00115 . \mathrm{x}$

[70] Eraut M. Learning from other people in the workplace. Oxford Review of Education. 2007; 33(4): 403-22. https ://doi . org/10.1 080/03054980701425706

[71] Billett S. Guided Learning at Work. Journal of Workplace Learning: Employee Counselling Today. 2000; 12(7): 272-85. https: //doi.org/10.1108/13665620010353351 